\title{
Grand Challenges in Geohazards and Georisks
}

\author{
Gordon Woo* \\ Risk Management Solutions (RMS), London, UK \\ Keywords: geohazards, georisks, challenges, warning, mitigation, loss
}

\section{INTRODUCTION}

The interface between Earth scientists and georisk stakeholders is a critical part of the safety infrastructure of society. Everyone is exposed to some degree of earthquake risk; some may also be exposed to flood, landslide, avalanche, tsunami and volcanic risk. Collectively, corporations, civic authorities, local and national governments are also important georisk stakeholders. Whilst the number of stakeholders is very many, the number of Earth scientists is comparatively few. The interface between the many and the few is crucial. Yet it is not well served by the existing scientific and technical literature.

Currently, papers relevant for stakeholders are widely scattered across numerous journals in the geoscientific, civil engineering, risk and public policy literature. There is inadequate crossreferencing between these journals, which have a narrow technically specialized readership. Consequently, it is very difficult for any citizen, public official, or private safety manager to form a coherent view of international best practice in geohazards and georisks.

Best practice in georisk management needs to be shared with the wider stakeholder community.

Edited by:

Valerio Acocella,

Roma Tre University, Italy

Reviewed by:

Valerio Acocella,

Roma Tre University, Italy

Andy Nicol,

University of Canterbury, New Zealand Jacopo Selva,

Istituto Nazionale di Geofisica e

Vulcanologia, Italy

*Correspondence:

Gordon Woo

gordonwoo@rms.com

Specialty section: This article was submitted to Geohazards and Georisks, a section of the journal

Frontiers in Earth Science

Received: 12 August 2016

Accepted: 15 February 2017

Published: 02 March 2017

Citation:

Woo G (2017) Grand Challenges in

Geohazards and Georisks.

Front. Earth Sci. 5:19.

doi: 10.3389/feart.2017.00019
Yet specific technical information about many important risk projects is left unpublished for lack of an appropriate journal. The study of geohazards and georisks is a multi-disciplinary global subject that needs to have its own specialist journal adapted for the internet age. The open access e-publishing revolution at last makes this possible.

Existing journals tend to serve primarily either the hazard or the risk community, and to polarize their readership according to their scientific or technical, academic or professional backgrounds. The combination of both Geohazards and Georisks in the title of this new journal in itself is indicative of its basic purpose and objective, and intended broad outreach to the wider community of academics, professionals and practitioners.

Geohazards and Georisks will have a strong emphasis on real practical geohazard and georisk applications, and will publicize interesting studies and projects that use state-of-the-art geohazard and georisk methods, and highlight best practice. These studies and projects may be in the government, corporate, insurance, or NGO sectors, and may be anywhere in the world. In the developing world, open access to published studies would be of particular importance. The interchange of ideas and techniques across the barriers of economic sector and geography will overcome the restrictions of the prevailing knowledge silo system. Of particular interest will be contributions that present practical viable solutions to the serious geohazard and georisk problems that beset society in the Twenty-first century. These solutions may leverage a combination of Earth science and social science.

A key objective of the journal is to promote innovation and see the most advanced scientific knowledge and understanding applied to geohazard assessment and georisk mitigation and management. All too often, there is a long delay of many years, even decades, before superior methods are adopted for practical risk mitigation purposes. Innovative methods of quantitative hazard and risk analysis may be published, but yet remain unfamiliar to risk stakeholders. Techniques devised in one georisk domain may be unnecessarily and belatedly re-invented in another. 
Geohazards and Georisks aims to be a leading open access portal for Earth scientists and risk stakeholders to learn from others in discovering better ways of evaluating hazards and managing risks across the spectrum of practical safety applications. The journal will contribute to the priorities of the Sendai Framework for Disaster Risk Reduction and showcase progress in addressing the following ten grand challenges listed here (UNISDR, 2015).

\section{CHALLENGE 1: CHARTING EXTREME SCENARIOS}

Geohazard analysts are too often surprised by so-called "Black Swans" or unknown unknowns: extreme rare events that occur without apparent historical precedent or past geological evidence. A grand challenge for the whole subject area of geohazards and georisks is to be surprised less by such extreme rare events, for which there may be all too little preparation, mitigation or risk awareness. "Grey Swan" events which are known but are difficult to model also merit special attention.

In each hazard domain, the concept of a maximum credible event needs to be refined and established on a sounder quantitative basis. In regions where large events are uncommon, the tail of the extreme event distribution can be explored by making more extensive use of evidence from the historical and geological past. More thorough assessment is needed of what has previously happened, or what nearly happened, or might have happened.

\section{CHALLENGE 2: DYNAMIC COUPLING OF GEOHAZARDS}

Extreme geohazards are sometimes coupled together through explicit or implicit dynamic interactions. Improving the understanding of such coupling is a grand challenge for the future of Earth Science in general, and for the study of geohazards and georisks in particular. Event clustering is of significant practical concern for the aggravated risk posed, and for the added pressure on a resilient societal response. In particular, building vulnerability to multiple events is not well analyzed.

The triggering mechanisms linking earthquakes with volcanic eruptions and vice versa need to be better modeled and understood. Within seismology itself, the triggering of one earthquake by another is a critical issue in seismic hazard assessment, and the long distance interactions between great earthquakes needs to be better understood.

Massive tsunamis may be generated from major earthquakes, volcanic eruptions and landslides. Floods may also be generated by earthquakes.

\section{CHALLENGE 3: CRITICAL INFRASTRUCTURE PROTECTION}

A grand challenge for any country is the protection of its lifelines and other critical infrastructure from geohazards. Resilience has become a crucial goal for infrastructure protection. However, the means of achieving resilience, and even the definition of resilience itself, vary from one geohazard domain to another. Coherent multi-hazard approaches to enhancing resilience need to be established, and studies addressing multiple geohazards need to be undertaken and published for the benefit of all stakeholders.

Often detailed hazard studies are undertaken for specific key sites. Broader dissemination of the knowledge gained from site investigations would enhance national hazard and risk mapping. For example, a multi-hazard site-specific study may identify geological evidence of fault movement or liquefaction; or identify susceptibility to tsunamis or storm surges.

\section{CHALLENGE 4: QUANTITATIVE GEOHAZARD AND GEORISK ASSESSMENT}

Probabilistic approaches to both geohazard and georisk assessment have developed progressively over the past half century, but there is substantial scope for further advancement, especially in the area of model calibration and validation. Improved methods for dealing with epistemic uncertainty are needed for quantitative risk assessment and comparison with deterministic approaches to managing risk. The manner and circumstances in which deterministic approaches are implemented also merit investigation.

All geohazards have a specific spatial context, whereby increased resolution in hazard assessment requires both local and regional investigation. Accordingly, major advances in geohazard and georisk assessment are often tied to stakeholder requirements and interests. Progress in raising the technical level of geohazard and georisk assessment is expedited by the publication of summaries of site-specific studies for significant projects. Too often, reports of interesting application studies are left unread in the gray literature.

\section{CHALLENGE 5: SOCIAL AND ECONOMIC DISRUPTION ANALYSIS}

The loss consequences of a major geohazard event are numerous and complex. Assessment of impact is facilitated by enhancements in the accuracy of mapping hazard intensities, the evaluation of building vulnerability, and in capturing high quality data on the changing urban landscape and building exposure. The epistemic uncertainty in risk analyses needs to be reduced.

Digital mapping and spatial data acquisition aid greatly the task of social and economic disruption analysis. Modern technology tools, such as satellite imagery, remote sensing, UAV etc., serve to address the ongoing grand challenge of upgrading the resolution of disaster impact studies.

Indirect causes of loss can be a significant factor in the overall level of societal disruption. The complexity of urban society leads to emergent loss phenomena which need to be better understood. Enhancements in the resolution of population mapping, even in remote areas of the planet, allow the humanitarian cost of population displacement to be assessed more reliably. The quantification of business interruption is an 
open challenge to georisk analysts and insurers seeking to manage this more effectively.

\section{CHALLENGE 6: GEOHAZARD WARNINGS}

Each geohazard poses a threat that requires the issuance of a public warning, to the extent that this is scientifically feasible, affordable and effective. The literature on hazard warnings is fragmented amongst many diverse journals, and unpublished technical reports. This impedes the development of a coherent approach to geohazard warning, where lessons learned in one hazard domain may advance progress in another hazard domain, and encourage innovation. For example, raising the skill level in forecasting techniques is key to meeting the challenge of improving geohazard warnings.

With the acquisition of increasing quantities of monitoring data, much of it digital, new methods for data synthesis are needed to maximize the warning information that can be gleaned, and used in a practical way for public protection.

Decision makers responsible for issuing geohazard warnings have much to learn from each other in the manner in which difficult decisions are made under substantial uncertainty, balancing population safety against economic disruption, recognizing the limits to public tolerance of false alarms.

Few publication opportunities currently exist for sharing warning procedures and protocols with both stakeholders and other decision makers.

\section{CHALLENGE 7: GEORISK MITIGATION}

Financial resources for georisk mitigation are strictly limited, especially during times of austerity. Optimal allocation of resources for georisk mitigation is hard to achieve using ad hoc methods. Cost-effective mitigation requires a coherent riskinformed approach, comparing the implementation costs and the risk mitigation benefits. A grand challenge is to develop better and more effective ways of mitigating risks which can be shown to be economically justified.

New pathways for financing risk mitigation need to be developed based on demonstrating the cost-effectiveness of preventing loss in advance rather than paying for loss afterwards. This would accord with the Sendai Framework priority of building back better.

The collective expertise of economists, insurers and financiers must supplement the technical knowledge and experience of georisk analysts. There is ample scope for financial initiative in promoting the modern agenda for georisk mitigation.

\section{CHALLENGE 8: DECISION MAKING FOR PUBLIC SAFETY}

Traditional approaches for making geohazards decisions relating to public safety have developed over centuries and are slow to change. Risk-informed decision methods have the potential for making more rational, equitable, and defensible safety decisions. A grand challenge is to promote the development and implementation of transparent, reliable and robust risk-informed approaches to decision making on geohazards and georisks.

Even where informal decision conference methods are used to make safety decisions, more accountability and transparency are desirable. Decision making under uncertainty involves an irreducible element of expert judgment. Structured methods of eliciting expert judgment should be encouraged.

\section{CHALLENGE 9: PUBLIC EDUCATION}

There are serious deficiencies in the technical information on geohazards and georisks openly available for public education. An informed public is a safer public. Broadening the base of public knowledge of the hazards to which populations are exposed is a major challenge of the Twenty-first century. Everyone is a stakeholder in risk mitigation. An open access publication enables everyone, including the least knowledgeable, to find the most relevant and current information about a specific hazard of interest.

A common frustration with the existing status quo is that much of the technical literature is inaccessible because of a payment barrier. Search for high quality reliable geohazard and georisk information should be free like a Google search. This would help to correct an information availability bias whereby unreliable and misinformed opinion, not subject to peer review, may dominate the public discourse.

\section{CHALLENGE 10: PUBLIC COMMUNICATION}

Public communication of geohazards and georisks is the final grand challenge. Action to mitigate risk depends crucially on effective public communication. Discussion of public communication of hazards and their uncertainties is mainly contained within the social science or risk literature. Earth scientists have little familiarity with this literature. Accordingly, the interface with the geohazards and georisks literature is very narrow. But Earth scientists need to have some knowledge of the frontiers in the public communication of science.

\section{AUTHOR CONTRIBUTIONS}

The author confirms being the sole contributor of this work and approved it for publication.

\section{REFERENCES}

UNISDR (2015). Sendai Framework for Natural Disaster Reduction 2015-2030. http://www.unisdr.org/we/coordinate/sendai-framework

Conflict of Interest Statement: The author declares that the research was conducted in the absence of any commercial or financial relationships that could be construed as a potential conflict of interest.

Copyright (c) 2017 Woo. This is an open-access article distributed under the terms of the Creative Commons Attribution License (CC BY). The use, distribution or reproduction in other forums is permitted, provided the original author(s) or licensor are credited and that the original publication in this journal is cited, in accordance with accepted academic practice. No use, distribution or reproduction is permitted which does not comply with these terms. 